\title{
Randomized trial: inflammatory response to corticoids versus placebo in moderate and severe bronchiolitis. COTHEBstudy.
}

\author{
Aida Felipe \\ Hospital Sant Joan de Deu \\ Mònica Balaguer \\ Hospital Sant Joan de Deu \\ Carme Alejandre \\ Hospital Sant Joan de Deu \\ Elisabeth Esteban \\ Hospital Sant Joan de Deu

\section{Laia Alsina} \\ Hospital Sant Joan de Deu \\ Carmen Muñoz-Almagro \\ Hospital Sant Joan de Deu \\ Maria Esther Esteban \\ Universitat de Barcelona \\ Francisco José Cambra \\ Hospital Sant Joan de Deu \\ lolanda Jordan ( $\square$ ijordan@hsjdbcn.org ) \\ Hospital Sant Joan de Deu https://orcid.org/0000-0002-2041-4425
}

Research article

Keywords:

Posted Date: May 28th, 2020

DOl: https://doi.org/10.21203/rs.2.22864/v2

License: (1) (i) This work is licensed under a Creative Commons Attribution 4.0 International License. Read Full License 


\section{Abstract}

Background: The use of corticosteroids has been shown not to improve the prognosis of patients with bronchiolitis, but it could be assumed that steroids will reduce inflammation. This study aimed to assess whether corticoid therapy influenced the inflammatory and clinical response of critically ill infants.

Methods: Prospective, randomized, double blind placebo-controlled trial of glucocorticoids (GCT) in infants of less than 12 monthswith severe or moderate bronchiolitis. Patients were randomized to receive systemic corticoid therapy or placebo. The main outcomes were: a) levels of lymphocyte subsets; b) levels of IL-2, IL12 , and IFNY as pro-inflammatory factors, and c) levels of IL-4 and IL-10 as anti-inflammatory response. Secondary outcomes related with the clinical response were also analyzed.

Results: 97 patients were randomized. Evolution of lymphocyte subsets was similar in both groups. Proinflammatory interleukins and interferon decreased, but without differences. Anti-inflammatory interleukins showed a significant decrease from baseline to the end of the study, and IL-10 values were significantly lower $(p=0.046)$ in the GCT group [1.82 pg/ml (1.2-3.5)] vs non-GCT [4 pg/ml (1.5-6.3)]. GCT group showed a lower time of mechanical ventilation and of hospitalization, but without statistically significant differences. No cases of severe adverse reaction to steroids were detected.

Conclusions: administration of systemic GCT did not modify the inflammatory nor the clinical response of patients with severe bronchiolitis, except for IL-10 levels that were significantly lower in the GCT group. This can open a line of investigation about the relation of IL-10 and response to bronchiolitis.

Trial registration: Glucocorticoid Therapy Impact on the Inflammatory Response and Clinical Evolution in Patients With Severe Bronchiolitis, Clinical Trials.gov registration number: NCT02571517.Study start date: Nov 2011.

\section{Background}

\section{What is already known on this topic:}

It has been shown that corticosteroids do not improve the clinical response to bronchiolitis. The specific inflammatory effect has not been established, but given their known mechanism of action it could be assumed that steroids will reduce inflammation.

\section{What this study adds:}

Systemic corticoids did not modify inflammatory or clinical responses. IL-10 levels were significantly lower in the corticoid group. Corticoid seems to decrease one day of mechanical ventilation. The study is not powered enough to make conclusions about duration of mechanical ventilation 
Bronchiolitis is mainly caused by respiratory syncytial virus (RSV) although other viruses can be also responsible for this infection ${ }^{1-2}$. This is one of the leading causes of infant hospitalization, with around $10 \%$ of cases admitted to the paediatric intensive care units $(\mathrm{PICUs})^{3-5}$ with high burden of healthcare costs ${ }^{1,6,7,8}$.

Paediatric patients with bronchiolitis have a massive neutrophil infiltration that contributes to stopping viral replication but may damage lungs and promote later asthma in severe cases ${ }^{9-10}$.The contact between the virus and the epithelial respiratory cells, with toll-like receptors (TLR), activates a local inflammatory response with cytokine that boosts cellular immunity to the infection site. This regulates the activity of $T$ and $B$ cells, improving the virus clearance or, increasing disease severity ${ }^{10-12}$ such as occurs when the Th1 and Th2 subpopulations of $C D 4+T$ cells produce imbalanced cytokines. Th1 lymphocytes produce tumor necrosis factor-alpha (TNFa) and interferon-gamma (IFNY) which enhance the inflammatory response, whereas Th2 lymphocytes produce interleukins 4 (IL-4), 5 (IL-5), 13 (IL-13), which are associated with the promotion of IgE and IL-10 showing an anti-inflammatory response. A prevalence of either Th1 or Th2 cytokines or even a mixed Th1-Th2 inflammatory response has been reported in different studies, with contradictory results that point out the complexity of the regulatory mechanisms that modulate the inflammatory/anti-inflammatory response in bronchiolitis ${ }^{13-17}$.

Although the treatment of bronchiolitis with corticosteroids is not recommended, it could be assumed that steroids, because of their mechanism of action, will reduce inflammation. Once corticoids are linked to their receptors in the cytosol, the receptor-glucocorticoid complex can either up-regulate the expression of antiinflammatory proteins in the nucleus (IL-4, IL-10, IL-13) or repress the expression of pro-inflammatory proteins in the cytosol (TNF- $a$, IL-1 a, IL- $\beta$, IFNy, IL-2, IL-3, IL-5, IL-6, IL-8, IL-12) ${ }^{18}$. Different trials have brought inconsistent results ${ }^{19}$. The guidelines of bronchiolitis published in 2014 do not recommend the administration of systemic corticosteroids to infants with a diagnosis of bronchiolitis in any setting ${ }^{20}$. The use of inhaled bronchodilators has also shown inconsistent results ${ }^{21}$. The Canadian Bronchiolitis Epinephrine Steroid Trial showed, however, a reduction in hospitalizations at 7 days after treatment with combined nebulized epinephrine and oral dexamethasone as compared with placebo, but it was only one large trial ${ }^{22}$. Both, the heterogeneous definition of bronchiolitis and the differences among trial designs regarding the reported outcomes affect the strength of evidence, especially in critical patients ${ }^{19,21}$.

On the basis of the controversy about treatment, it was designed a prospective, randomized, double blind placebo-controlled trial of glucocorticoids in infants of less than 12 months with severe or moderate bronchiolitis to determine whether corticoid therapy influenced the inflammatory response and clinical evolution of critically ill children. We measured a set of interleukins and cytokines as markers of pro- and anti-inflammatory response, as well as different lymphocyte subsets at baseline and at day 7 (end of treatment). Other outcomes related with the clinical response of the patients were also analysed.

\section{Methods}

Single-center, prospective, randomized, double blind, controlled, comparative, interventional clinical trial, conducted in the hospitalization and the pediatric intensive care units of the Hospital Sant Joan de Déu 
(Esplugues de Llobregat, Barcelona, Spain).

Time: From November 2011 to April 2014 (last update October 2015). The study was approved by the Ethics Committee of the Sant Joan de Déu Hospital, with EUDRA registration number CT 2011-000337-36. The study was registered at ClinicalTrials.gov with number NCT02571517. Parents received an information sheet and signed written informed consent prior to the inclusion of infants in the study.

Inclusion criteria: patients less than 12 months of age with severe or moderate bronchiolitis. Exclusion criteria: lack of informed consent, inclusion in other clinical trials, minor bronchiolitis or apnea as a main symptom, previous corticoid therapy, and primary immunodeficiency.

Bronchiolitis was defined according to the guidelines of the American Academy of Pediatrics $2006^{6}$. Patients with a bronchiolitis score BROSJOD $\geq 6$ moderate to severe crises) were eligible for the study ${ }^{23}$.

A research team collected parents' consent, demographic (age, sex, ethnic group) and physical (weight, BROSJOD score, Pediatric Risk of Mortality PRISM-II and underlying disease on admittance) data. The infant was then randomly assigned to receive systemic corticoid therapy (oral or endovenous) or placebo. Patient allocation either to the systemic glucocorticoid therapy group (GCT) or the control group (placebo, non-GCT group) was done by generating a binary series of random numbers ('random' function of MS-Excel $\mathrm{XP}{ }^{\circledR}$ for Windows $\left.{ }^{\circledR}\right)$. This procedure generated an equivalent random number of patients in both groups that was only available to the pharmacist who was responsible for preparing the two different treatments. Treatments had the same appearance and only the pharmacist who prepared them knew their composition. Patients, clinicians, nurses, and investigators were blind to treatment allocation.

Daily trial interventions in the GCT group were performed using methylprednisolone e.v. in a dose of 1 $\mathrm{mg} / \mathrm{kg}$ (twice a day, every 12 hours) or with equivalent doses of prednisolone p.o. in a dose of $1.25 \mathrm{mg} / \mathrm{kg}$ (twice a day, every 12 hours). In the non-GCT group (placebo), the treatment contained intravenous sodium chloride $(\mathrm{NaCl}) \mathbf{0 . 9 \%}$. or $5 \%$ oral glucose sodium chloride (twice a day, every 12 hours).

Date range for participant recruitment was from November 2011 to April 2014. Patients follow-up included one month after the trial inclusion day, and the last patient follow-up finished on October 2015.

Trial intervention was for a maximum of 7 days in accordance with previous studies reporting an improvement in the inflammatory response ${ }^{24-26}$. When patients improved sufficiently within the first days so as to receive hospital discharge, they were removed from the study.

Apart from the intervention of the trial, all patients were treated as follows: patients under conventional mechanical ventilation (MV) were treated with inhaled salbutamol on demand (auscultation with bronchospasm, or prolonged expiration). Patients with noninvasive ventilation (NIV) were tested for bronchodilator treatment at time of admission. Adrenaline or salbutamol were administered depending on patient age ( $<6$ months or $>6$ months, respectively). If the BROSJOD score decreased 2 or more points after treatment, then the bronchodilator treatment was continued every 4-6 or 8 hours. 
Common analytical data were recorded, including lymphocytes, leukocytes, and neutrophils. Lymphocyte subsets (CD4 and CD8) were determined with multiparametric flow cytometry in whole blood. Interleukins and IFNy were assessed by means of solid phase enzyme-labelled chemiluminescent immunometric assays. Tests for reference values were performed following the manufacturer's procedures. The etiology of bronchiolitis was determined by multiplex protein chain reaction in respiratory samples.

The main outcomes, measured at baseline and day 7 (end of intervention), consisted of: a) levels of lymphocyte subsets, b) levels of IL-2, IL-12, and IFNy, and c) levels of IL-4 and IL-10. Although sample size was not calculated for this, secondary outcomes related with the clinical response were recorded and compared when possible: need for PICU admission; length of PICU stay and total length of stay (LOS); occurrence of community-acquired bacterial infection, or nosocomial infection; duration of inotropes, MV, NIV, and high flow nasal cannula (HFNC); need for other rescue breathing-treatments (nitric oxide, high frequency mechanical ventilation, extracorporeal membrane oxygenation); need for continuous renal replacement therapy; occurrence of multiple organ failure; and in-hospital mortality at 28 days.

Considered deviations from the protocol: consent not correctly done or not done; non-compliance with the inclusion or exclusion criteria; lack of clinical or analytical data at the baseline visit or performed outside the established period; failure of the study blind; action performed by a researcher who is not the one indicated; inadequate drug or blind doses.

Data were introduced on a clinical record form and were treated as strictly confidential.

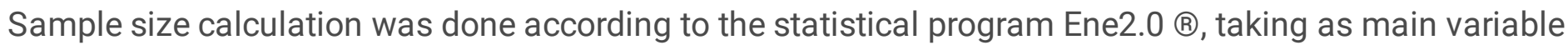
the existence of differences in the inflammatory response and clinic evolution of patients with moderatesevere bronchiolitis treated with methylprednisolone/prednisolone compared to those receiving placebo. The null hypothesis $(\mathrm{HO})$ was equality of means between the two treatments to be administered (placebo and methylprednisolone/prednisolone) and the alternative hypothesis $(\mathrm{H} 1)$ was the existence of differences between the two treatments. Considering a power of $80 \%$ to detect differences and a level of significance of 0.05 , and assuming that the proportion in the reference group was 0.5 , the proportion in the experimental group of 0.8 , and that the proportion of units experimental in the reference group with respect to the total was $50 \%$ it was be necessary include 39 patients in each group according to the results of the treatment with systemic corticosteroids from previous studies already commented.

After an exploratory analysis, sample size was recalculated and a final sample size of 50 patients in each group was obtained. Per-protocol analysis of primary and secondary outcomes was made by means of chisquare for categorical data, $t$ - test for quantitative variables, and Mann-Whitney test for non-parametric data. Normality was assessed through a Kolmogorov-Smirnov test. Paired data were compared through a Wilcoxon signed ranks test. The SPSS ${ }^{\circledR}$ statistical software package 22.0 (SPSS, Inc., Chicago, III) and R software ${ }^{27}$ were used to perform the statistical analyses.

\section{Results}


A total of 327 patients were assessed for eligibility but many of them declined to participate, 97 patients were randomised. One patient was excluded because parents revoked consent, two others due to lack of protocol compliance, and three others because it was required to unbind treatment allocation to allow them to receive additional glucocorticoid therapy. Finally, 53 subjects were assigned to the GCT group, and 44 to the placebo (Figure 1). Table 1 shows the main demographic and clinical data. Other recruited variables were etnia (caucasian in 69, 71.1\%), comorbidities (18, 18.5\%) and PICU admission (94, 96.9\%), no significant differences were found with respect to the treatment group.

Table 1. Demographic and clinical variables between groups at admission.

\begin{tabular}{|c|c|c|c|}
\hline Demographic and clinical variables & $\begin{array}{l}\text { Glucocorticoid Therapy (GCT) } \\
\qquad N=53\end{array}$ & $\begin{array}{c}\text { Non-GCT } \\
\mathrm{N}=44\end{array}$ & $\mathrm{P}$ value \\
\hline Age in days (median, IQR) & $45(23-73)$ & $42.5(24.7-90.7)$ & $0.951^{\mathrm{a}}$ \\
\hline Male sex (\%) & $28(52.8)$ & $24(54.5)$ & $0.866^{\mathrm{b}}$ \\
\hline Weight in $\mathrm{Kg}$ (median, IQR) & $4.0(3.5-4.9)$ & $3.9(3.3-5)$ & $0.999^{\mathrm{a}}$ \\
\hline \multicolumn{4}{|l|}{ Clinical variables } \\
\hline PRISM II (median, IQR) & $3(0-4)$ & $3(0.75-6)$ & $0.227^{\mathrm{a}}$ \\
\hline BROSJOD score (mean, SD) & $8.99(2.67)$ & $9.12(3.20)$ & $0.767^{\mathrm{C}}$ \\
\hline $\begin{array}{l}\text { Virus infection (\%) } \\
\quad 1 \text { virus } \\
\quad \geq 2 \text { viruses }\end{array}$ & $\begin{array}{c}43(87.7) \\
6(12.2)\end{array}$ & $\begin{array}{l}33(76.7) \\
10(23.3)\end{array}$ & $0.164^{\mathrm{b}}$ \\
\hline $\begin{array}{l}\text { Virus type (\%) } \\
\text { RSV } \\
\text { Rhinovirus } \\
\text { Other* }\end{array}$ & $\begin{aligned} 43 & (72.9) \\
5 & (8.5) \\
11 & (18.6)\end{aligned}$ & $\begin{array}{l}40(71.4) \\
9(16.1) \\
7(12.5)\end{array}$ & $0.356^{\mathrm{b}}$ \\
\hline $\begin{array}{l}\text { Lung auscultation (\%) } \\
\text { Normal } \\
\text { Bronchospasm } \\
\text { Crackle } \\
\text { Mixed }\end{array}$ & $\begin{aligned} 1 & (1.9) \\
4 & (7.5) \\
45 & (84.9) \\
3 & (5.7)\end{aligned}$ & $\begin{array}{c}- \\
- \\
40(90.9) \\
4(9.1)\end{array}$ & $0.538^{\mathrm{d}}$ \\
\hline $\begin{array}{l}\text { Skin color (\%) } \\
\text { Normal } \\
\text { Cyanosis } \\
\text { Bad peripheral revascularization }\end{array}$ & $\begin{array}{c}50(94.3) \\
- \\
3(5.7)\end{array}$ & $\begin{aligned} 42 & (95.4) \\
1 & (2.3) \\
1 & (2.3)\end{aligned}$ & $0.999^{\mathrm{e}}$ \\
\hline $\begin{array}{l}\text { Ventilation (\%) } \\
\text { No need } \\
\text { Mechanical ventilation } \\
\text { Non-invasive ventilation }\end{array}$ & $\begin{array}{l}22(41.5) \\
17(32.1) \\
14(26.4)\end{array}$ & $\begin{array}{l}17(38.6) \\
19(43.2) \\
8(18.2)\end{array}$ & $0.457^{\mathrm{b}}$ \\
\hline $\begin{array}{l}\text { X-ray respiratory pattern (\%) } \\
\text { Normal } \\
\text { Interstitial } \\
\text { Alveolar } \\
\text { Mixed } \\
\text { Atelectasis } \\
\text { Alveolar + atelectasis }\end{array}$ & $\begin{array}{c}\mathrm{N}=48 \\
- \\
4(8.3) \\
21(43.7) \\
7(14.6) \\
8(16.7) \\
8(16.7)\end{array}$ & $\begin{array}{l}\mathrm{N}=40 \\
1(2.5) \\
3(7.5) \\
21(52.5) \\
5(12.5) \\
5(12.5) \\
5(12.5)\end{array}$ & $0.918^{\mathrm{e}}$ \\
\hline
\end{tabular}

IQR: interquartile range 25-75. PRISM- Pediatric Risk of Mortality. BROSJOD-bronchiolitis score. *Other included adenovirus, metapneumorvirus, parainfluenza, bocavirus, enterovirus and coronavirus. 
${ }^{a}$ Probability value of Mann-Whitney U test; ${ }^{b}$ Probability value of Chi-square test; ${ }^{c}$ Probability value of Student- $t$ test; ${ }^{d}$ Crackle vs the rest of categories have been compared through the Fisher exact test; ${ }^{e}$ Normal vs the rest of categories have been compared through the Fisher exact test; ${ }^{f}$ Normal respiratory pattern has been excluded for Chi-square test calculation.

The main immunological outcomes between days 1 and 7 are shown in Table 2.

Table 2. Immunological outcomes between groups. Levels are indicated as median (IQR). GCT sample size 36; nonGCT sample size 29. 


\begin{tabular}{cccc}
\hline Immunological Outcomes & Baseline & End of study & $\mathrm{P}^{\mathrm{a}}$ \\
& Day 1 & Day 7 & \\
\hline
\end{tabular}

Total Leukocytes in $\times 10^{9} / \mathrm{L}$, mean (SD)

$\begin{array}{lccc}\text { GCT } & 8.6(4.3) & 12.4(4.6) & <0.001 \\ \text { Non-GCT } & 8.8(3.2) & 12.0(4.0) & 0.001 \\ \text { Student's t-test } P_{\text {GCT vs non-GCT }} & 0.733 & 0.707 & \end{array}$

Total Lymphocytes in $\times 10^{6} / \mathrm{L}$, mean (SD)

GCT $\quad 3.9(2.4) \quad 5.5(2.3)<0.001$

Non-GCT $3.7(1.5) \quad 5.1(2.2)<0.001$

Student's t-test $\mathrm{P}_{\mathrm{GCT}}$ vs non-GCT $\quad 0.109 \quad 0.630$

Total Neutrophils in $\times 10^{9} / \mathrm{L}$, mean (SD)

GCT

Non-GCT

Student's t-test $\mathrm{P}_{\mathrm{GCT}}$ vs non-GCT

\begin{tabular}{|c|c|c|c|}
\hline & Baseline & End of study & $\mathrm{P}^{\mathrm{b}}$ \\
\hline \multicolumn{4}{|l|}{$\mathrm{IL}-2 *$ in $\mathrm{pg} / \mathrm{ml}$} \\
\hline GCT & $5.2(4.6-5.8)$ & $0(0-0)$ & 0.026 \\
\hline Non-GCT & $5.3(4.6-6.2)$ & $2.5(0-5.3)$ & 0.075 \\
\hline Mann-Whitney U-test $P_{G C T}$ vs non-GCT & 0.999 & 0.350 & \\
\hline \multicolumn{4}{|l|}{ IL-4*inpg/ml } \\
\hline GCT & $1.3(1.2-1.7)$ & $0(0-1.2)$ & 0.019 \\
\hline Non-GCT & $1.2(1.1-1.2)$ & $0(0-0)$ & 0.285 \\
\hline Mann-Whitney U-test $P_{G C T}$ vs non-GCT & 0.999 & 0.900 & \\
\hline \multicolumn{4}{|l|}{$\mathrm{IL}-10$ in $\mathrm{pg} / \mathrm{ml}$} \\
\hline GCT & $13.6(3.6-25.4)$ & $1.82(1.2-3.5)$ & $<0.001$ \\
\hline Non-GCT & $17.5(7-39.8)$ & $4(1.5-6.3)$ & $<0.001$ \\
\hline Mann-Whitney U-test $P_{\mathrm{GCT}}$ vs non-GCT & 0.230 & 0.046 & \\
\hline \multicolumn{4}{|l|}{$\mathrm{IL}-12 *$ in $\mathrm{pg} / \mathrm{ml}$} \\
\hline GCT & $6.0(5.5-6.4)$ & $4.7(0-6.7)$ & 0.263 \\
\hline Non-GCT & $3.9(3.7-4.7)$ & $0(0-6.3)$ & 0.715 \\
\hline Mann-Whitney U-test $P_{\mathrm{GCT}}$ vs non-GCT & 0.026 & 0.461 & \\
\hline
\end{tabular}

IFN $\gamma$ in $\mathrm{mg} / \mathrm{ml}$

GCT

Non-GCT

Mann-Whitney U-test $\mathrm{P}_{\mathrm{GCT}}$ vs non-GCT

CD4/CD8

GCT

Non-GCT

Mann-Whitney U-test $\mathrm{P}_{\mathrm{GCT}}$ vs non-GCT
$3.2(2.3)$

$3.6(2.1)$

0.422

$5.3(2.9)$

$5.5(3.4) \quad 0.008$

$<0.001$

0.828 $0.725 \quad 0.916$

* Only patients with IL values $>0$ at baseline were considered. $\mathrm{P}^{\mathrm{a}}$ : Students'ttest probability for paired samples baseline $v s$ end of study; $\mathrm{P}^{\mathrm{b}}$ : Wilcoxon signed ranks test probability for paired samples baseline vs end of study.

Lymphocyte subsets ratio (CD4 and CD8) increased from day 1 to day 7 without significant differences between treatment groups. Pro-inflammatory (IL2, IL-12, and IFNy) and antiinflammatory (IL-4 and IL-10) markers decreased between day 1 and day 7. The decrease was statistically significant in all cytokines except for IL12 in both groups, and IL-2 and IL-4 in the placebo group. The only significant difference between treatment groups was observed for IL-10 values at the end of the study ( $p=0.046)$ (Figure 2). The CD4/CD8 ratio also decreased along the study without differences between groups.

No significant differences were detected $2.8(2.3-3.7) \quad 1.9(0.7-2.4)<0.001$ with regard to secondary outcomes as 2.9 (2.1-3.4) $1.8(1.2-2.3)<0.001$ inotropic or respiratory support requirements, bacterial coinfection and nosocomial infection, and length of PICU and hospital stay (Table 3). Even

though the GCT group showed, on average, one day less of PICU stay, as well as one day less of MV and NIV. With respect to other outcomes: only one patient required HFVO (in the GCT group); no patients were supported with renal replacement support, and none had MOF or dead during the evolution.

Adverse events did not show differences between treatment groups (Supplemental content). Only three nonsevere adverse events were detected, all in the GCT group. In all cases, the children recovered without 
consequences.

Table 3. Secondary outcomes. Values are indicated as median (IQR) and $\mathbf{n}(\%)$.

\begin{tabular}{|c|c|c|c|}
\hline Days of hospitalization and ventilation & $\begin{array}{c}\text { GCT } \\
\mathrm{n}=53\end{array}$ & $\begin{array}{c}\text { Non-GCT } \\
n=44\end{array}$ & $P$ value ${ }^{a}$ \\
\hline & $\begin{array}{c}\mathrm{n}(\%) \\
\text { (median, p25-75) }\end{array}$ & $\begin{array}{c}\mathrm{n}(\%) \\
\text { (median, p25-75) }\end{array}$ & \\
\hline Inotropic days & $\begin{array}{l}11(20.7) \\
2.9(1-3.5)\end{array}$ & $\begin{array}{c}9(20.4) \\
3.3(2.1-3.9)\end{array}$ & \\
\hline Days of mechanical ventilation & $\begin{array}{l}19(35.8) \\
6(5-8)\end{array}$ & $\begin{array}{l}15(34.1) \\
7(4-8)\end{array}$ & 0.999 \\
\hline Days of non-invasive ventilation & $\begin{array}{c}44(83) \\
3(2.1-5)\end{array}$ & $\begin{array}{l}38(86.3) \\
4(2-5)\end{array}$ & 0.767 \\
\hline Days of HFNC & $\begin{array}{c}15(28.3) \\
3(1-4)\end{array}$ & $\begin{array}{c}10(22.7) \\
4.5(2-5.2)\end{array}$ & 0.160 \\
\hline Total days of mechanical + non-invasive ventilation & $\begin{array}{c}19(35.8 \%) \\
9(7-11)\end{array}$ & $\begin{array}{l}15(34.1) \\
9(7.5-10)\end{array}$ & 0.732 \\
\hline Community-acquired bacterial infection & $8(15.1)$ & $7(15.9)$ & 0.815 \\
\hline Nosocomial bacterial infection & $4(7.5)$ & $3(6.8)$ & 0.950 \\
\hline Total length of stay in the hospital & $\begin{array}{c}53(100 \%) \\
11(8-16.5)\end{array}$ & $\begin{array}{c}44(100 \%) \\
11.5(9-16.7)\end{array}$ & 0.796 \\
\hline Days PICU stay & $\begin{array}{c}44(83) \\
6(4.2-10)\end{array}$ & $\begin{array}{l}39(88.6) \\
7(4-10)\end{array}$ & 0.883 \\
\hline In-hospital mortality at 28 days & 0 & 0 & - \\
\hline
\end{tabular}

GCT: Glucocorticoid treatment. PICU: Pediatric Intensive Care Unit. HFNC: High-flow nasal cannula. MOF: multiple organ failure. ${ }^{a}$ Mann-Whitney U test.

\section{Discussion}

Regarding the main objective of this study, the administration of systemic corticoids did not significantly modify the inflammatory and clinical response of our patients. In spite of being a homogeneous group of infants less than 12 months of age with an episode of moderate-severe bronchiolitis, the systemic inflammatory response was very similar in the group treated with glucocorticoids and in the placebo group.

Baseline leukocyte and neutrophil count values were found in the low levels of normality in both groups, whereas the lymphocyte count was found in the upper range of age reference values. All these values significantly increased at the second determination, without differences between groups. It is well known that viral infections can debut with a drop in the white cell account, mainly in the number of neutrophils, whereas the lymphocyte count can vary ${ }^{1,9}$. Presumably, the administration of glucocorticoids would increase these numbers since it generates the onset of leukocytosis trough neutrophilia. The fact that the 
GCT group did not show a higher count as compared with the placebo group at the end of the study may be explained by the fact that the duration of the treatment was only 5-7 days.

Pro-inflammatory interleukins and interferon, classically described as activators of the inflammatory response in patients with bronchiolitis, decreased in both treatment groups. Predictably, at baseline, the values were higher after the stimulus generated by the virus responsible for the infection. In the second determination, the natural immune response of the individual would be able to diminish such activation, even in the absence of glucocorticoids. In our study, the GCT group did not show a decrease in a more marked way. It should be noted that, in our study, IL-2, IL-12, and IFNy already showed remarkably low levels at baseline. This fact is in accordance with a previous study that found that the younger the infants with bronchiolitis, the lower the levels of interleukins and interferon ${ }^{28}$. The median age of our patients was 45 days, and thus antiviral immunity, and more specifically antiviral T-cells, could be diminished because of the immaturity of the neonatal immune system ${ }^{29}$. Interleukin values in the second determination were practically undetectable, as it has also been described in other studies after 3-4 weeks following baseline determination ${ }^{28}$.

Anti-inflammatory interleukins IL-4 and IL-10 showed a significant decrease from baseline to the end of the study. IL-10 values at the end of treatment were significantly lower in the GCT group in comparison with the placebo group. Again, it would seem that patients by themselves were able to regulate the anti-inflammatory response by diminishing IL-10 levels after the initial infectious stimulus. In our patients, the inflammatory and anti-inflammatory responses seemed to evolve in a parallel way, independently of the administration of glucocorticoids. However, the significantly lower final levels of IL-10 in the GCT group as compared with the placebo group could be a relevant result. A previous study suggested that higher IL-10 levels in the convalescent phase of patients with RSV bronchiolitis were associated with recurrent wheezing throughout the year after the infection ${ }^{30}$. If this finding is confirmed in future studies, the use of glucocorticoids could be recommended for hospitalized patients or for severe cases of bronchiolitis.

The relationship among the pattern of cytokines and glucocorticoids was also explored in a previous study analyzing tracheal aspirates of children with severe bronchiolitis. The authors concluded that dexamethasone did not show any significant effect on the concentrations of 25 cytokines and chemokines involved in the inflammatory response of this infection ${ }^{31}$.

Given the complexity of the inflammatory response in bronchiolitis, a second objective was proposed aiming at evaluating whether glucocorticoids influenced the clinical evolution of patients, independently of the analytical results. The group treated with glucocorticoids showed one day less of PICU length of stay, MV, NIV and HFNC ventilation in comparison to the placebo group, although the differences were not statistically significant. The mean duration of mechanical ventilation was 1.6 days shorter in a previous study comparing dexamethasone and placebo, and the difference was also not statistically significant ${ }^{32}$.

Although it has been reported that the infectious etiology of bronchiolitis does not affect outcomes, some studies have linked specific pathogens of bronchiolitis to short- and long-term outcomes and the risk of developing asthma. Influenza virus, for example, showed higher levels of IFNy (marker of Th1 response) and 
IL-4 (marker of Th2 response) as compared with RSV and metapneumovirus. With regard to the clinical severity, no differences were detected either for the hospital admission rate or for the presence of bronchospasm among patients infected with influenza, RSV, or metapneumovirus ${ }^{33-34}$. Other publications have reported that bronchiolitis by rhinovirus showed a good response to GCT therapy, improving clinical symptoms and showing less risk of wheezing recurrence as compared with placebo ${ }^{35}$. In our study, the low number of patients infected with viruses other than RSV does not allow us to draw any solid conclusion. Probably the benefit of GCT might be influenced by the viral etiology of the bronchiolitis due to the different inflammatory response caused by the different respiratory viruses.

No cases of severe adverse reaction attributable to the treatment with glucocorticoids were detected in our study. Three patients with non-severe adverse events were reported. The total number of infections was similar in the systemic GCT and placebo groups. These infections were more likely due to the risk of nosocomial infection of patients admitted to the PICU, the secondary immunosuppression of these patients, and the use of invasive devices.

Although our patients were less than 3 months of age, no cases of hepatic, renal, or hematological toxicity were detected. Likewise, no patients with arterial hypertension or severe hyperglycemia, two of the most common side effects of systemic corticotherapy,

were observed, nor did any suffer suprarenal insufficiency after treatment. Consistent with this, studies analyzing the use of corticoids in cases of acute respiratory distress syndrome (ARDS) have reported that the use of high doses of methylprednisolone $(30 \mathrm{mg} / \mathrm{kg} / 6 \mathrm{~h}$ ) for a short period (one day) increased the risk of ARDS and death. However, more recent studies concluded that lower doses of methylprednisolone (1-2 $\mathrm{mg} / \mathrm{kg} /$ day) for at least 1-4 weeks showed beneficial effects on the morbidity and mortality of patients, with scarce adverse events ${ }^{18}$.

The reduced sample size is the main limitation of this trial especially with regard to the clinical outcomes, although this limitation is a problem detected in most studies in pediatrics, such as those discussed in this paper $28-30,34,35$. Furthermore, the fact that not all the patients had an available central line for blood extractions, together with their low age, meant that in some cases there was not enough sample available to determine all the variables included in the study. For this reason, the sample size of interleukins, interferon, and lymphoid populations was lower than the number of patients recruited. Otherwise, this clinical trial was not designed in order to analyse this secondary outcomes. The homogeneity of the recruited patients in terms of age, severity, clinical presentation, and evolution could partially overcome these limitations.

\section{Conclusion}

The results of this study allow us to conclude that the administration of systemic GCT did not modify the inflammatory and clinical response of very young patients with moderate or severe bronchiolitis, except for IL-10 levels that were significantly lower in the GCT group as compared with the placebo one.

Given the epidemiological and clinical relevance of bronchiolitis and the high health care resources consumed, more clinical trials are needed to conclude on the efficacy of a corticoid therapy, and also on the 
impact on such treatment on IL-10, and its possible effect on future wheezing. These trials should ideally recruit a greater number of patients, with homogeneous criteria of severity (validated clinical scores) and with different branches of mixed therapeutic options to be useful, especially in patients with severe bronchiolitis.

\section{Abbreviations}

ARDS: Acute Respiratory Distress Syndrome,

GCT: Glucocorticoids,

HFNC: High Flow Nasal Cannula,

IFNY: Interferon-gamma,

Ig: Immunoglobulin,

IL: Interleukin,

LOS: Length of stay,

MV: Mechanical ventilation,

$\mathrm{NaCl}$ : Sodium chloride,

NIV: Non invasive ventilation,

PICU: Pediatric Intensive Care Unit,

RSV: Respiratory Syncytial Virus,

TLR: Toll Like Receptors,

TNFa: Tumor Necrosis Factor-alpha

\section{Declarations}

-Ethics approval and consent to participate: The study was approved by the Ethics Committee of the Hospital Sant Joan de Déu with the reference and registered at ClinicalTrials.gov with EUDRA registration number CT 2011-000337-36, ClinicalTrials.gov registration number: 2011-000337-36. Parents received an information sheet and signed written informed consent prior to the inclusion of infants in the study.

-Consent to publish: Not applicable.

-Availability of data and materials: All data generated or analysed during this study are included in this published article [and its supplementary information files]. 
-Competing interests: The autors declare that they have no competint interests.

-Funding: This study was financially supported by Official Grant from Spanish Health Ministry. The funding was in order to invoice the trial assurance, the Contract Research Organization and the analytical expenses and the statistical analysis. No other institutions have financed this research. Authors disclose any potential financial or ethical conflicts of interest regarding the contents of this submission. The authors have no conflicts of interest to this article to disclose.

\section{-Authors' contributions:}

-Dr IJ conceptualized and designed the study, designed the data collection instruments, collected data, coordinated and supervised data collection, analysis and interpretation of data, drafted the initial manuscript and reviewed and revised the manuscript.

-Dr AF, contribution to conception and design, acquisition of data, or analysis and interpretation of data, drafting the article or revising it critically for important intellectual content, final approval of the version to be published, agreement to be accountable for all aspects of the work in ensuring that questions related to the accuracy or integrity of any part of the work are appropriately investigated and resolved.

-Dr CA, contribution to conception and design, acquisition of data, or analysis and interpretation of data, drafting the article or revising it critically for important intellectual content, final approval of the version to be published, agreement to be accountable for all aspects of the work in ensuring that questions related to the accuracy or integrity of any part of the work are appropriately investigated and resolved.

-Dr EE, contribution to conception and design, acquisition of data, or analysis and interpretation of data, drafting the article or revising it critically for important intellectual content, final approval of the version to be published, agreement to be accountable for all aspects of the work in ensuring that questions related to the accuracy or integrity of any part of the work are appropriately investigated and resolved.

-Dr LA, contribution to conception and design, acquisition of data, or analysis and interpretation of data, drafting the article or revising it critically for important intellectual content, final approval of the version to be published, agreement to be accountable for all aspects of the work in ensuring that questions related to the accuracy or integrity of any part of the work are appropriately investigated and resolved.

-Dr CMA, contribution to conception and design, acquisition of data, or analysis and interpretation of data, drafting the article or revising it critically for important intellectual content, final approval of the version to be published, agreement to be accountable for all aspects of the work in ensuring that questions related to the accuracy or integrity of any part of the work are appropriately investigated and resolved.

-Dr MEE, contribution to conception and design, acquisition of data, or analysis and interpretation of data, drafting the article or revising it critically for important intellectual content, final approval of the version to be published, agreement to be accountable for all aspects of the work in ensuring that questions related to the accuracy or integrity of any part of the work are appropriately investigated and resolved. 
-Dr FJL, contribution to conception and design, acquisition of data, or analysis and interpretation of data, drafting the article or revising it critically for important intellectual content, final approval of the version to be published, agreement to be accountable for all aspects of the work in ensuring that questions related to the accuracy or integrity of any part of the work are appropriately investigated and resolved.

-Dr MB, contribution to conception and design, acquisition of data, or analysis and interpretation of data, drafting the article or revising it critically for important intellectual content, final approval of the version to be published, agreement to be accountable for all aspects of the work in ensuring that questions related to the accuracy or integrity of any part of the work are appropriately investigated and resolved.

All authors approved the final manuscript as submitted and agree to be accountable for all aspects of the work.

-Acknowledgements: Notapplicable.

\section{References}

1. Ogra PL. Respiratory syncytial virus: the virus, the disease and the immune response. Paediatr Respir Rev2004;5(SuppIA):S119-26.

2. Mansbach JM, Piedra PA, Teach SJ, et al. Prospective multicenter study of viral etiology and hospital length of stay in children with severe bronchiolitis. Arch Pediatr Adolesc Med2012;166:700-706.

3. Richard N, Komurian-Pradel F, Javouhey E, et al. The impact of dual viral infection in infants admitted to a pediatric intensive care unit associated with severe bronchiolitis. Pediatr Infect Dis J2008;27:213-217.

4. Heikkilä P, Forma L, Korppi M. Hospitalisation costs for infant bronchiolitis are up to 20 times higher if intensive care is needed. Acta Paediatr2015;104:269-273.

5. Ramos-Fernández JM, Pedrero-Segura E, Gutiérrez-Bedmar M, et al. Epidemiology of patients hospitalised due to bronchiolitis in the south of Europe: Analysis of the epidemics, 2010-2015. AnPediatr (Barc). 2016.pii: S1695-4033(16)30274-0.

6. Subcommittee on Diagnosis and Management of Bronchiolitis. Diagnosis andManagement of Bronchiolitis. Pediatrics2006;118:1774-1793.

7. Nair H, Nokes DJ, Gessner BD, al. Globalburden of acute lower respiratory infections due to respiratory syncytial virus in young children: a systematic review and meta-analysis. Lancet2010; 375:1545-155.

8. Sly PD, Kusel M, Holt PG. Do early-life viral infections cause asthma? J Allergy Clin Immunol 2010;125:1202-1205.

9. Geerdink RJ, Pillay J, Meyaard L, et al. Neutrophils in respiratory syncytial virus infection: A target for asthma prevention. J Allergy Clin Immuno2015;136:838-847.

10. Reed JL, Welliver TP, Sims GP, et al. Innate immune signals modulate antiviral and polyreactive antibody responses during severe respiratory syncytial virus infection. J Infect Dis2009; 199:1128-1138.

11. Bueno SM, González PA, Pacheco R, et al. Host immunity during RSV pathogenesis. Int Immunopharmacol2008; 8:1320-1329. 
12. Tripp RA. Pathogenesis of respiratory syncytial virus infection. Viral Immunol2004;17:165-181.

13. Bendelja K, Gagro A, Bace A, et al. Predominant type-2 response in infants with respiratory syncytial virus (RSV) infection demonstrated by cytokine flow cytometry. Clin Exp Immunol2000;121:332-338.

14. Mobbs KJ, Smyth RL, O'Hea U, et al. Cytokines in severe respiratory syncytial virus bronchiolitis. Pediatr Pulmonol 2002;33:449-452.

15. Legg JP, Hussain IR, Warner JA, et al. Type 1 and type 2 cytokine imbalance in acute respiratory syncytial virus bronchiolitis. Am J RespirCrit Care Med2003;168:633-639.

16. Pinto RA, Arredondo SM, Bono MR, et al. T helper $1 / \mathrm{T}$ helper 2cytokine imbalance in respiratory syncytial virus infection is associated with increased endogenous plasma cortisol. Pediatrics2006;117:e878-886.

17. Moreno-Solís G, Torres-Borrego J, de la Torre-Aguilar MJ, et al. Analysis of the local and systemic inflammatory response in hospitalized infants with respiratory syncytial virus bronchiolitis. Allergol Immunopathol2015;43:264-271.

18. Thompson BT. Corticosteroids for ARDS. Minerva Anestesiol2010;76:441-447.

19. Fernandes RM, Bialy LM, Vandermeer B, et al. Glucocorticoids for acute viral bronchiolitis in infants and young children. Cochrane Database Syst Rev2013;6:CD004878.

20. Ralston SL, Lieberthal AS, Meissner HC, et al. Clinical practice guideline:The diagnosis, management, and prevention of bronchiolitis. Pediatrics2014;134:e1474-e1502.

21. Gadomski AM, Scribani MB. Bronchodilators for bronchiolitis. Cochrane Database Syst Rev2014;6:CD001266.

22. Plint AC, Johnson DW, Patel H, et al. Pediatric Emergency Research Canada (PERC).Epinephrine and dexamethasone in children withbronchiolitis. N Engl J Med2009;360:2079-2089.

23. Balaguer M, Alejandre C, Vila D, et al. Bronchiolitis Score of Sant Joan de Déu: BROSJOD Score, validation and usefulness. Pediatr Pulmonol2017;52:533-539.

24. Alansari K, Sakran M, Davidson BL, et al. Oral dexamethasone for bronchiolitis: a randomized trial. Pediatrics2013;132:e810-816.

25. Tagarro A, Pérez L, Quintero VM, et al. Dexamethasone does not reduce length of hospitalization or recurrent wheezing 1 year after early bronchiolitis. Minerva Pediatr2014;66:131-40.

26. Fernandes RM, Hartling L. Glucocorticoids for acute viral bronchiolitis in infants and young children. JAMA2014;311:87-88.

27. R Core Team (2013). R: A language and environment for statistical computing. R Foundation for Statistical Computing, Vienna, Austria.URL http://www.R-project.org/.

28. Bont L, Heijnen CJ, Kavelaars A, et al. Peripheral blood cytokine responses and disease severity in respiratory syncytial virus bronchiolitis. Eur Respir J1999;14:144-149.

29. Holt PG. Postnatal maturation of immune competence during infancy and childhood. Pediatr Allergy Immunol1995;6:59-70.

30. Bont L, Heijnen CJ, Kavelaars A, et al. Monocyte IL-10 production during respiratory syncytial virus bronchiolitis is associated with recurrent wheezing in a one-year follow-up study. Am J RespirCrit Care 
Med2000;161:1518-1523.

31. Somers CC, Ahmad N, Mejias A, et al. Effect of dexamethasone on respiratory syncytial virus-induced lung inflammation in children: results of a randomized, placebo controlled clinical trial. Pediatr Allergy Immunol2009;20:477-485.

32. Van Woensel JB, Wolfs TF, van Aalderen WM, et al. Randomised double blind placebo controlled trial of prednisolone in children admitted to hospital with respiratory syncytial virus bronchiolitis. Thorax1997; 52:595-597.

33. Hasegawa K, Mansbach JM, Camargo CA Jr. Infectious pathogens and bronchiolitis outcomes. Expert Rev Anti Infect Ther2014;12:817-828.

34. Melendi GA, Laham FR, Monsalvo AC, et al. Cytokine profiles in the respiratory tract during primary infection with human metapneumovirus, respiratory syncytial virus, or influenza virus in infants. Pediatrics2007;120:e410-415.

35. Jartti $T$, Lehtinen $P$, Vanto $T$, et al. Evaluation of the efficacy of prednisolone in early wheezing induced by rhinovirus or respiratory syncytial virus. Pediatr Infect Dis J2006; 25:482-488.

\section{Figures}




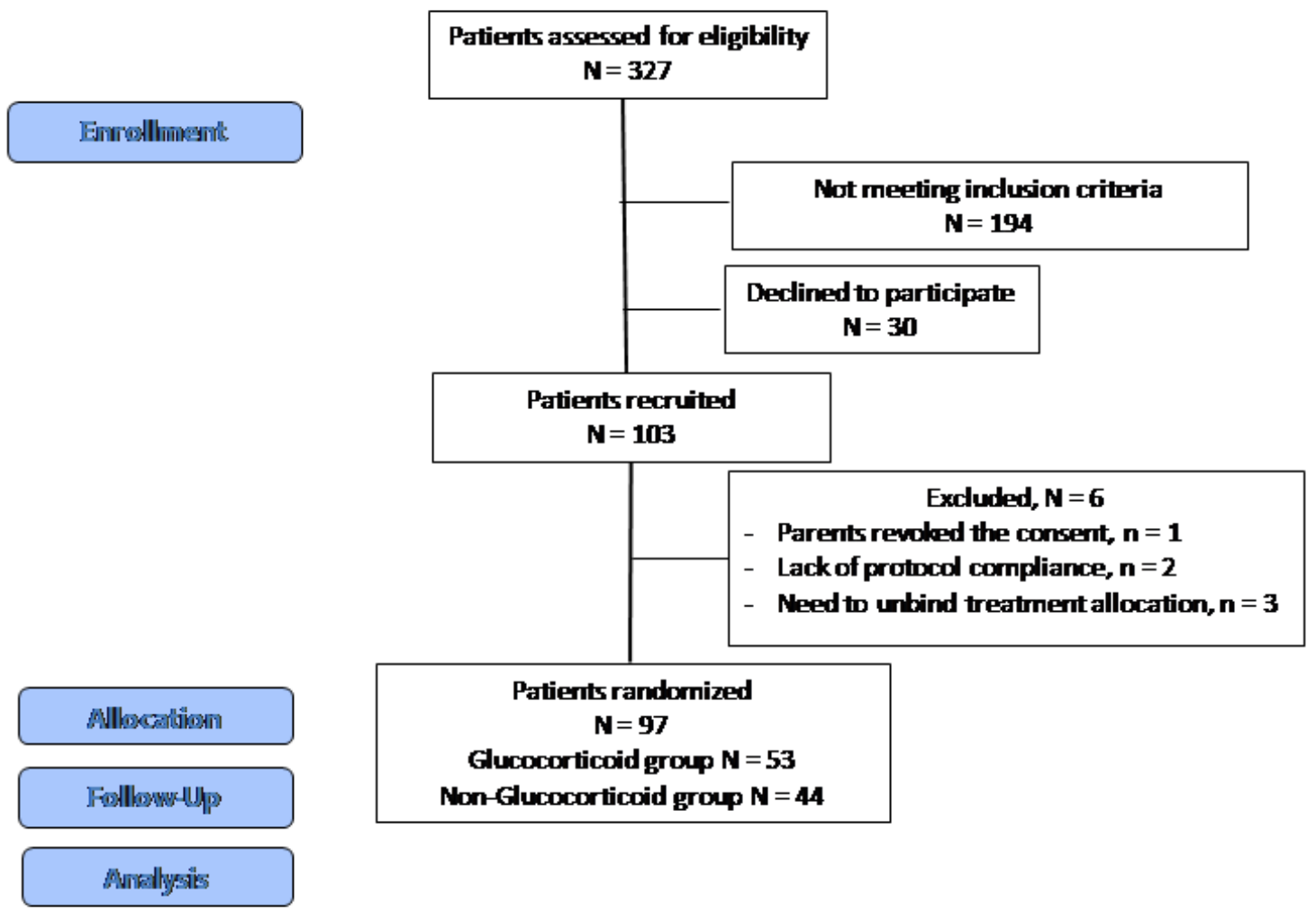

Figure 1 Screening, errollment and treatment of patients

\section{Figure 1}

Screening, enrollment and treatment of patients. 
IL10 baseline between groups

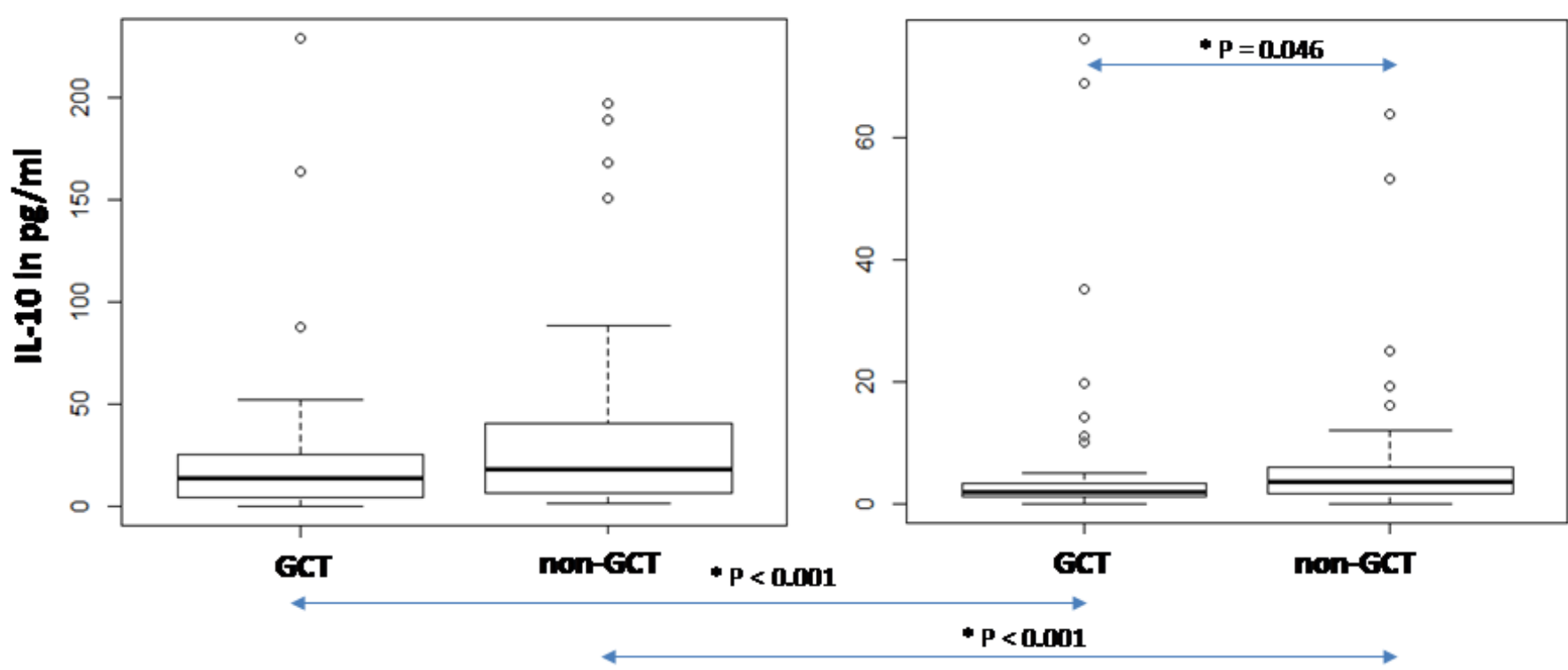

Figure 2 IL-10 measurements between GCT and placebo (non-GCT) groups at baseline and at the end of the study* Arrows indicate statistically significant differences

Figure 2

IL-10 measurements between GCT and placebo (non-GCT) groups at baseline and at the end of the study. * Arrows indicate statistically significant differences.

\section{Supplementary Files}

This is a list of supplementary files associated with this preprint. Click to download.

- SuplementalTable.doc

- ConsortForm.docx 